\title{
BMJ Open Older care home residents' and their relatives' knowledge, understanding and views of shift handovers: an exploratory, focused-ethnographic qualitative study using interviews and observations
}

Katharine Orellana (1) , Valerie Lipman (D) , Jill Manthorpe (1) , Jo Moriarty (1) , Caroline Norrie (D) , Rekha Elaswarapu

To cite: Orellana K, Lipman V, Manthorpe J, et al. Older care home residents' and their relatives' knowledge, understanding and views of shift handovers: an exploratory, focused-ethnographic qualitative study using interviews and observations. BMJ Open 2019;9:e032189. doi:10.1136/ bmjopen-2019-032189

- Prepublication history and additional material for this paper are available online. To view these files, please visit the journal online (http://dx.doi. org/10.1136/bmjopen-2019032189).

Received 08 June 2019 Revised 06 November 2019 Accepted 11 November 2019

Check for updates

(c) Author(s) (or their employer(s)) 2019. Re-use permitted under CC BY-NC. No commercial re-use. See rights and permissions. Published by BMJ.

NIHR Policy Research Unit in Health and Social Care Workforce, The Policy Institute at King's, King's College London, London, UK

Correspondence to

Dr Katharine Orellana;

katharine.orellana@kcl.ac.uk

\section{ABSTRACT}

Objectives To investigate residents' and relatives' views and experiences of handovers in care homes. This paper reports residents' and relatives' awareness of handovers, knowledge of and views on handover practices and purpose, and views on handover effectiveness. Outcomes, safety and satisfaction in clinical settings are influenced by shift handovers. Despite this link with quality, residents' increasing support needs and the provision of 24 hours care in care homes for older people, little is known about handovers in these settings from a resident and visiting relative perspective.

Setting Five purposively sampled care homes for older people in South East England.

Participants Home managers $(n=5)$, residents $(n=16)$ relatives of residents $(n=10)$ were interviewed; residents $(n=15)$ and their interactions with staff were observed during handover periods. Participation was voluntary and subject to consent. Residents were identified by managers as having mental capacity to take a decision about participation which was then assessed. An ethnographic approach to data collection was taken, preceded by an evidence review.

Results Shift handovers were largely invisible processes to participating residents and relatives, many of whom had given little thought to handover practice, logistics or effectiveness prior to study participation. Their awareness and understanding of handovers, handover practices, and handover purpose and effectiveness varied. There appeared to be an underlying assumption that administrative procedures in care homes would operate without input from residents or relatives. A small number of residents, however, were highly aware of the routine of handovers and the implications of this for the timing of and response to their requests for care or support.

Conclusions The care home setting and perspectives of the effectiveness of handovers may influence awareness of, knowledge of and levels of interest in involvement in handovers.

\section{Strengths and limitations of this study}

- Combining observations with interviews provided additional insight into handover periods, creating two complementary data sources.

- Data collection and analysis were strengthened by the varied professional backgrounds (social work, mental health nursing, nursing, gerontology, health and social care, regulation) and subject expertise (includes workforce, dementia, older people, care homes, dignity, equality and diversity, safeguarding, voluntary sector, user involvement, lay inspection) of the project team of the six female university researchers of mixed ages.

- Maximum variation sampling of care homes increased diversity across participating care homes, in that the only shared characteristic was being rated as 'Good' by the Care Quality Commission, the independent regulator of health and social care in England; therefore, the generally good practice observed may not cover the range of care homes.

- The resident sample had the capacity to consent to being observed and interviewed; less cognitively intact residents are under-represented in this study.

- Agreement to participate was lower among residents of Asian backgrounds despite sampling a care home with high resident numbers from this group.

\section{BACKGROUND}

People generally move to care homes late in life, when they are frail. ${ }^{1}$ At least $80 \%$ of older care home residents have dementia or other significant cognitive impairment. ${ }^{2}$ In England, 'care home' refers to care facilities providing accommodation, meals and personal care which are divided into those 'with' or 'without' nursing care. ${ }^{3}$ Both are regulated by the Care Quality Commission (CQC); those 'with nursing' (often referred 
to as nursing homes) are required to have a registered nurse always on duty.

Several studies undertaken in clinical settings have identified handover of information between 'outgoing' and 'incoming' shifts as a key element influencing outcomes, patient safety and satisfaction. ${ }^{4-6}$ There is considerable research on nurse handovers in hospitals ${ }^{7}$ and a small, but growing, body of research about patient perspectives of or involvement in handovers, for example,. ${ }^{68-12}$ Little attention has been paid, though, to handovers in residential care settings, with or without nursing, which is surprising given the overlap between care home residents and hospital patients in terms of their support needs. As in 24 hours clinical settings, at least two changes of shift occur daily in every care home. ${ }^{7}$ Handovers-whether between nurses, care workers, nurses and care workers, with or without the involvement of senior managersmay be an important element in ensuring good, consistent quality of care for residents although the CQC does not specifically monitor their quality. The growth of the person-centred approach to care-which centres on understanding the person receiving care, engaging that person in decision-making and promoting the care relationship ${ }^{13}$ - and encouragement of user involvement to improve services make the resident perspective potentially important in handover practice.

We previously conducted a study of staff perspectives of the content, purpose and effectiveness of handovers in care homes for older people. ${ }^{14}$ We now report a subsequent complementary investigation into older care home residents' and their visiting relatives' views and experiences of handovers in care homes which addressed three questions: (1) what do residents think about the way staff communicate at the start and end of shifts and do they like what happens? (2) Do relatives know what the home's practice is, have they views on it and how do they think handovers affect residents? (3) What can observation of residents during handover periods tell us about a home's culture and working ethos. Our studies aim to inform staff and regulator reflection on good practice in handovers and we recognise that quality is a multi-faceted concept. This paper focuses on awareness of the occurrence of handovers, knowledge of handover purpose and logistical practices, and handover effectiveness from residents' and relatives' perspectives. Handovers' potential impact on residents' well-being will be reported separately.

\section{METHODS}

As our study aimed to focus on a specific set of views and experiences during a specific event that is influenced by organisational cultures, namely handovers, we took an exploratory, focused-ethnographic ${ }^{15}$ qualitative approach.

According to Wall's ${ }^{15}$ synopsis of the development of focused ethnography, traditional ethnography aims to describe cultural behaviours, generally without addressing a formal research question, involves long-term fieldwork and is usually undertaken by researchers outside, and without experience of, the culture being studied. Focused ethnography is a type of micro-ethnography especially useful in addressing specific problems in fragmented and specialised study areas. Researchers with background knowledge of the study topic enter the field with specific research questions and short-term visits are undertaken with a defined subcultural group of participants.

Handovers are influenced by organisational cultures ${ }^{16}$ which may be described as the way in which things are done, or ways of behaving in a given work setting, whether this is a particular location (such as a hospital ward or care home) or a wider field (such as types of care homes). Adopting this perspective means that handovers can be seen as rituals in organisational settings.

Principles of maximum variation sampling ${ }^{17}$ were applied in the recruitment of care homes as this is a very varied sector. A purposive sample of five homes in the South East region of England with different characteristics was recruited from a sample matrix, constructed after identifying homes through researcher contacts and internet searches, of 16 potential care homes which undertook handovers either in or just outside residents' rooms (room-by-room) or in other locations (eg, office, lounge). As homes with less satisfactory CQC reports declined to participate in our previous study, we included only homes awarded a rating of Good or Outstanding. Managers/owners were then invited to take part, consecutively, to achieve our target of five care homes. Two did not respond. Three refused as they thought they would contribute little, either because they were small homes with handovers that were said to last only a few minutes, or because of the small proportion of residents with capacity to undertake an interview (although not registered for people with dementia). One agreed to remain on the reserve list should another withdraw. Another initially agreed to participate but was replaced when it became clear that residents did not meet inclusion criteria and its owner-manager offered another home in its place. Five homes were not approached as our sample target had been reached. One care home participated in both studies. Table 1 gives details of the participating homes and table 2 summarises timings, location and coverage of shift handovers, as reported by managers.

Data collection was undertaken from March to July 2018. The study consisted of semi-structured interviews, with prompts, with five care home managers, 16 residents and 10 relatives, and observations of 15 of the interviewed residents. Target recruitment of residents and/or relatives was five per care home. Participants totalled 31. The fieldwork team consisted of five researchers with varied expertise and backgrounds. Residents' and relatives' data in three homes were gathered by a single researcher and, in two sites, two researchers undertook data collection in each. The lead study researcher visited all five care homes and interviewed three managers, jointly with another researcher in one home; the researchers gathering resident and relative data in the other two homes interviewed 
Table 1 The study care homes $(n=5)$

\begin{tabular}{|c|c|c|c|}
\hline $\begin{array}{l}\text { Care home } \\
\text { (pseudonym) }\end{array}$ & $\begin{array}{l}\text { Type of care } \\
\text { home }\end{array}$ & Type of provider & Further details \\
\hline Clematis Grove & $\begin{array}{l}\text { Care home with } \\
\text { nursing }\end{array}$ & $\begin{array}{l}\text { Large for-profit } \\
\text { chain }\end{array}$ & $\begin{array}{l}\text { For } 150 \text { older people (and younger adults), people with dementia, } \\
\text { sensory impairments and physical disabilities, with one unit for } \\
\text { residents from an Asian background. CQC rating 'Good' ('Outstanding } \\
\text { in 'Caring' domain). } \\
\text { Of the three participating units, three were nursing and one was } \\
\text { residential; all had } 20 \text { rooms. A hybrid documentation system } \\
\text { operated, where care plans are electronic, but other notes are made } \\
\text { on paper. }\end{array}$ \\
\hline $\begin{array}{l}\text { Elderflower } \\
\text { House }\end{array}$ & $\begin{array}{l}\text { Care home } \\
\text { (without nursing) }\end{array}$ & $\begin{array}{l}\text { For-profit small } \\
\text { business }\end{array}$ & $\begin{array}{l}\text { For } 35 \text { older people, people with physical disabilities and people with } \\
\text { dementia. CQC rating 'Good'. } \\
\text { An electronic system is in place; members of staff use an application } \\
\text { (app) on their mobile phones to update daily handover notes at the } \\
\text { point of care. }\end{array}$ \\
\hline Tulip House & $\begin{array}{l}\text { Care home } \\
\text { (without nursing) }\end{array}$ & $\begin{array}{l}\text { Small, not-for- } \\
\text { profit chain }\end{array}$ & $\begin{array}{l}\text { For } 60 \text { older people, split into four units, each with 13-15 rooms. CQC } \\
\text { rating 'Good'; handovers commented on positively. } \\
\text { Handovers are verbal and use paper notes. }\end{array}$ \\
\hline Violet Manor & $\begin{array}{l}\text { Care home with } \\
\text { nursing }\end{array}$ & $\begin{array}{l}\text { Large, for-profit } \\
\text { chain }\end{array}$ & $\begin{array}{l}\text { For } 70 \text { older people with/without dementia. CQC rating 'Good'; } \\
\text { handovers commented on positively. } \\
\text { Comprises two units of similar size: for people requiring nursing or } \\
\text { with more advanced dementia. } \\
\text { Participants are linked to both units, but all participating residents } \\
\text { lived in the nursing unit. Handovers are verbal and use paper notes. }\end{array}$ \\
\hline
\end{tabular}

CQC, Care Quality Commission.

their managers. Table 3 provides a breakdown of resident and relative participants by care home and researchers undertaking data collection. Table 4 summarises participants' characteristics briefly to protect their anonymity.

Residents and relatives were given the opportunity to volunteer for interviews and/or observations via posters displayed in the care homes and by direct approach from the care home managers, whom they knew, who provided a study Information Sheet. Residents were identified by managers as having mental capacity to take a decision about participation. Researchers then spoke with or emailed potential participants. Since residents and relatives were approached by the care home managers, we are unable to quantify the refusal or drop-out rate of potential participants.

Individual observations $(\mathrm{n}=47)$ were undertaken during 30 handover periods over 23 days at different times of day (morning $\mathrm{n}=14$, day time $\mathrm{n}=3$, evening $\mathrm{n}=13$ ) during the week $(n=24)$ and at weekends $(n=6)$. We aimed to be as unobtrusive as possible to mitigate the risk that behaviour might change as a result of being observed. In vivo observations were recorded on a template devised for the study (see online supplementary file 1 ).
Interviews, which took place at the care homes, lasted 8-38 min with residents and $15-33$ min with relatives (see online supplementary file 2 for topics covered). A family member was present at one resident interview and a resident was also present at two relative interviews.

Before each interview, participants gave their consent, which followed a discussion with the researcher of the study's aims and methods. Interviews were digitally audiorecorded, except for three in which notes were taken due to recording consent being refused, a noisy environment making recording impractical, and recorder malfunction, respectively.

Transcriptions and notes of interviews were allocated reference numbers and entered into NVivo qualitative analysis software package, along with observational fieldnotes which were written up as soon as practically possible after visits, and which differentiated direct observations from interpretations using an approach based on Spradley and Rineharts work. ${ }^{18}$ Participants were not asked to check interview transcriptions. Combined interview and observational data were analysed from June to August 2018. Following inductive thematic coding in NVivo, data were further analysed using a matrix 
Table 2 Summary of shift handovers as reported by managers

\begin{tabular}{|c|c|c|c|c|c|}
\hline Care home & Clematis Grove & Elderflower House & Orchid Hall & Tulip House & Violet Manor \\
\hline $\begin{array}{l}\text { Number of daily } \\
\text { handovers }\end{array}$ & Two & Two or three & Two or three & Four & Two \\
\hline Day time & $\mathrm{N} / \mathrm{A}$ & $\begin{array}{l}14: 45-15: 00 \\
\text { (weekdays only) } \\
15 \text { min }\end{array}$ & $\begin{array}{l}\text { 13:45-14:00 (daily } \\
\text { nursing unit; not } \\
\text { daily residential unit) } \\
15 \text { min }\end{array}$ & $\begin{array}{l}\text { 14:00-14:05 } \\
5 \mathrm{~min} \\
\text { 16:00-16:05 } \\
5 \mathrm{~min}\end{array}$ & $\mathrm{~N} / \mathrm{A}$ \\
\hline Evening & $\begin{array}{l}20: 00-20: 15 / 20 \\
15-20 \mathrm{~min}\end{array}$ & $\begin{array}{l}\text { 19:50-20:05 } \\
15 \text { min }\end{array}$ & $\begin{array}{l}\text { 19:45-20:00 } \\
15 \text { min }\end{array}$ & $\begin{array}{l}21: 00-21: 15 \\
15 \min \end{array}$ & $\begin{array}{l}20: 00-20: 15 \\
15 \text { min }\end{array}$ \\
\hline Handover covers & $\begin{array}{l}\text { Each unit } \\
\text { separately }\end{array}$ & Entire home & Each unit separately & $\begin{array}{l}\text { Two units at } \\
\text { each handover }\end{array}$ & $\begin{array}{l}\text { Each unit } \\
\text { separately }\end{array}$ \\
\hline
\end{tabular}

approach to compare categories related to the research questions and identified themes. ${ }^{19}$ The first author undertook coding and initial analysis. Team meetings, which included an additional researcher not undertaking fieldwork, supported and further developed themes identified; data saturation was discussed in these. Three overarching themes resulted, two of which were relevant to this paper (see table 5 ).

A key concern was maintaining anonymity when, in each home, few people participated. Therefore, care homes are pseudonymised, bed numbers are rounded, participants' reference numbers do not indicate their home, and we use the term 'care worker', although some homes used other descriptors for direct care workers.

\section{Patient and public involvement}

The research question arose during our previous study of staff perspectives of how handovers happened ${ }^{14}$ in discussions with the Service User and Carer Group which supported the Unit's research. This group and an advisory group recruited for the project assisted by commenting on the planned methodology, data collection tools and emerging findings. Members included individuals with experience of visiting relatives in, working in or of being lay inspectors of care homes or of living in a care facility, representatives from third-sector organisations concerned with care homes and older people, and ethnographic researchers with experience of care home research. Their range of expertise, experiences and perspectives complemented the team's own. Gains from this involvement included increased numbers of planned observations to compensate for logistical barriers to interaction or observations at handover times (eg, residents sleeping or receiving personal care during handovers), refined interview questions, useful feedback on emerging findings and suggested future directions for further study.

A report and/or lay summary of findings was shared with study participants.

\section{FINDINGS}

This paper focuses on findings concerning residents' and relatives' awareness of the occurrence of handovers, their knowledge and views on handover purpose and of

Table 3 Resident and relative participants by care home, and team member undertaking data collection

\begin{tabular}{|c|c|c|c|c|c|c|}
\hline Care home & $\begin{array}{l}\text { Resident } \\
\text { and relative } \\
\text { participants }(n=26)\end{array}$ & $\begin{array}{l}\text { Residents } \\
\text { interviewed } \\
(n=16)\end{array}$ & $\begin{array}{l}\text { Relatives } \\
\text { interviewed } \\
(n=10)\end{array}$ & $\begin{array}{l}\text { Residents } \\
\text { observed } \\
(n=15)\end{array}$ & Interviewers & Observers \\
\hline Clematis Grove & 6 & 3 & 3 & 3 & RE & RE \\
\hline Elderflower House & 5 & 3 & 2 & 3 & KO & JoM \\
\hline Orchid Hall & 5 & 4 & 1 & 4 & $\mathrm{KO}$ and $\mathrm{CN}$ & CN \\
\hline Tulip House & 5 & 4 & 1 & 3 & VL & VL \\
\hline
\end{tabular}




\begin{tabular}{|c|c|c|c|}
\hline & $\begin{array}{l}\text { Number } \\
\text { interviewed }\end{array}$ & $\begin{array}{l}\text { Number } \\
\text { observed }\end{array}$ & Characteristics \\
\hline Residents & 16 & 15 & $\begin{array}{l}13 \text { female, three male } \\
\text { Aged 90-99: } 9 \\
\text { Aged 80-80: } 5 \\
\text { Aged 70-79: } 2\end{array}$ \\
\hline $\begin{array}{l}\text { Family } \\
\text { members }\end{array}$ & 10 & N/A & $\begin{array}{l}\text { Nine female, one male } \\
10 \text { children, two partners/ } \\
\text { spouses of residents } \\
\text { Aged } 70-79: 2 \\
\text { Aged } 60-69: 1 \\
\text { Aged } 50-59: 5 \\
\text { Refused age data: } 2 \\
\text { Length of time visiting in } \\
\text { the homes: } 2.5 \text { months-3 } \\
\text { years. Visiting patterns } \\
\text { ranged from daily to every } \\
7-10 \text { days, but most } \\
\text { visited more than three } \\
\text { times a week. } \\
\text { Six relatives reported } \\
\text { their relatives' cognitive } \\
\text { or communication } \\
\text { impairments precluded } \\
\text { discussion with them } \\
\text { about their care. }\end{array}$ \\
\hline
\end{tabular}

logistical handover practices, and their views on handover effectiveness.

\section{Awareness of the occurrence of handovers}

As table 2 shows, most handovers took place early in the morning or in the late evening. These were times when most residents were in their rooms which meant they did not see or hear handovers that took place in offices or elsewhere. Many residents were asleep during handovers; thus their experiences were limited to prehandover and posthandover encounters with care workers or nursing staff. These included staff greeting residents and bidding them farewell, delivering hot drinks and/or doing a round of the rooms 'checking up' on residents. Even when handovers were room-by-room, residents were not always awake, or did not necessarily associate being visited in their rooms by staff with the shift handover process.

All three Clematis Grove residents were aware that handovers happened at shift changeover, but only one of the two Violet Manor residents was aware that handovers

Table 5 Themes and sub-themes identified relevant to this paper

\begin{tabular}{ll}
\hline Overarching theme & Subthemes \\
\hline Awareness & $\begin{array}{l}\text { Awareness of the occurrence of } \\
\text { handovers } \\
\text { Awareness/knowledge of } \\
\text { handover practices }\end{array}$ \\
& $\begin{array}{l}\text { Views on purpose } \\
\text { Views on effectiveness } \\
\text { effectiveness }\end{array}$ \\
\hline
\end{tabular}

happened. The meeting in the lounge which she described as 'handover' was actually the posthandover meeting of incoming staff.

As for the handover times themselves, a small number of residents were aware that handovers happened at the times researchers told them. Some residents were aware of some handovers but not others. Some residents were not aware of any handovers. Some residents thought handovers happened $30 \mathrm{~min}$ later than they did. The few residents most aware of handovers and their timings were those who were less content with what they (residents) were doing at handover times or who reported having to wait, for toileting assistance, for example, at handover time.

The proportion of residents saying they did not know what happened when staff started and finished work was the same as those who were aware that incoming and outgoing staff met to speak with each other. A small number presumed care staff were preparing for their shift by taking their coats off and having a cup of tea; one thought staff were busy helping people get up at the morning handover time. Just over half of all residents said they were unaware of what care staff were doing during handover periods, all but one of whom lived in care homes where handovers were not carried out roomby-room. Interestingly, residents' views on what care staff were doing during handover periods did not always coincide with what they thought care staff did when they arrived for their shift or just before leaving after the end of a shift. One pointed out that a resident in their room does not see staff arrive. Another was being served breakfast by domestic staff and did not see care workers at these times; our observations in Tulip House confirmed this.

Some residents' responses suggested that they had not previously considered what staff were doing while not attending to them as individuals; they were also unaware of staff's additional duties (eg, to brief other staff):

I don't even know if they have meetings, or if they just come in and other others go out, you know. (...) We don't really, you know we don't really see much of what they do except when they're with $\underline{\text { us. }}$ Yeah, but you don't really think about it when you're in here.

(Resident 6) (emphasis in the original)

These residents' awareness of staff activity was limited to what staff did in their immediate environment:

I know myself what's happening to me. (Resident 2; emphasis in original)

For some, this reflected their lack of interest in the administration of the care home. For others, it was because they considered handovers to be staff business:

It doesn't affect me. (...) But I know it's to do with the staff, like a general, it's to do with the staff, that's a simple one. (Resident 1)

Family members were aware of shift times and locations, but fewer than half were fully aware of the handover times 
and locations. Relatives either did not visit at handover times or were in their relative's room when they took place. Despite the length of time some had been visiting their family member in the care home and the frequency with which some visited, only one relative reported being present during a room-by-room handover.

\section{Knowledge of and views on handovers practices and purpose}

Although some residents knew incoming and outgoing staff met to speak with each other, most had not heard or seen handover conversations and could only speculate about what happened at and who attended handovers. This mostly involved assumptions that their needs and health conditions were being discussed. However, two residents thought that staff were simply talking about them, as people, but felt it was good staff did talk about them and recognised their individuality:

I would say that they probably talk about us, I would think. I think I'm polite, and I think somebody's recognised that. (...) I'm quite fascinated really, they've probably all put us in boxes already, if you know what I mean. They know that I don't ring the bell very often. So, when I do ring it, on the whole, it's usually for a reason. (Resident 8 )

Living in a home that operated room-by-room handovers did not guarantee an understanding of handovers, their content and the processes they involved. Accounts differed between the three residents in one home operating room-by-room handovers in which staff were observed to actively involve residents during room-byroom handover discussions:

We just have a chat. [they ask] 'How are you today?' That's about all. (Resident 14)

... the day nurses who usually work here, of course, they usually come in about just after eight, because that's when they leave, and they'll wish me a good night and all that and then the other nurses take over then. (Resident 15)

On a morning, yeah. General chitchat. It's not much, you know, a few words. I mean I don't say much. (Resident 16)

One resident, speculating about handover content, repeatedly raised that staff have a habit of going back into their own tongue [language], you see. That's part of the problem ....' (Resident 15), meaning that staff did not converse in English during these meetings and their conversations were, therefore, inaccessible to him.

Relatives, generally, had a good idea of the purpose of handovers, believing these were for residents' continuous care and/or safety, for accountability and for making incoming staff aware of plans for the next shift, such as a resident's hairdressing appointment. However, they were unaware of managerial ideas about additional purposes of handovers: team planning/building, sharing policy/ procedure/training information, ${ }^{14}$ ensuring staff were aware of family dynamics and knew about all residents, not just the ones they were looking after, and for residents to know staff were interested in them, further purposes stated by manager participants.

Nevertheless, there was much speculation among family members about the minutiae of handovers. While one relative who had worked in care homes had experience of handovers, others did not, although many relatives speculated correctly that staff were briefed on residents' health needs and what had happened during the previous shift (including problems), and that relevant information or notes about these were being handed over. One thought this information was likely to be passed from nurse to nurse without any care worker involvement; another thought it was likely to be from nurse to nurse and care worker to care worker, depending on the subject.

Most relatives knew their family member had a care plan or 'file', but they did not know whether these were linked with handovers. Only two were aware of a handover file that staff wrote in. Another two knew that electronic records existed. Generally, relatives felt their involvement in handovers was unnecessary and were, hypothetically, only likely to be interested in seeing handover records should a problem arise.

As with the relative who was a former care worker, a handful of family members and residents stated that their awareness, knowledge and views of handovers had been influenced by their, or a family member's, work in nursing or social care.

Residents' awareness of and views on the length of handovers were relatively evenly divided, sometimes influenced by their own needs at these times. Some had no idea of how long handover conversations lasted; others considered they lasted a reasonable amount of time.

A subset of participants indicated that administrative matters, such as handovers, were not within their scope of interest and they, therefore, were unaware of handover length:

(And do you know how long the staff have conversations for when they change shift?) 'Not really. (...) Emmerdale's [TV series] more important [to me].' (Resident 7)

But at 9 o'clock at night I don't think I'd be terribly interested in what they're discussing, not in the slightest. (Resident 1)

Those least content with handover length were residents who were awake and needing or wanting assistance. A small number of relatives were concerned that the lack of visibility of staff at handover times meant that vulnerable residents were, potentially, not being attended to, but half had no concerns about residents while staff were busy doing handovers, feeling that residents were either sleeping or the period was covered by some other activity (eg, tea rounds). Not all relatives voiced views on this.

Three-quarters of participants felt they did not know enough about handovers to suggest potential 
improvements or reported being happy with the status quo and did not feel that changes were necessary. Only one participant (a relative) made a suggestion concerning the topic of this paper, expressing a wish for information about handovers to be part of the introduction to the home's routines, what relatives could expect and any related procedures.

\section{Views on handover effectiveness}

All relatives considered shift handovers to be beneficial for residents and/or themselves. Benefits for relatives mainly related to continuity of care; they gained peace of mind from knowing that staff were well-briefed on their family member's needs and health, awareness of potential medication needs relating to distressed behaviour, from knowing they would be made aware of any new problems, and benefited from staff informing them on arrival of their relative's health and well-being. One relative reported not having thought about handovers as beneficial for themselves before the interview.

None of the residents reported feeling as if their usual care staff did not know them, their needs and preferences but thought others/temporary staff might not, which may imply that this information may not be discussed in shift handovers. Whether or not handovers were viewed as useful emerged as something many had given little thought to before being interviewed for this study. While most believed, or assumed, that outgoing shifts passed on information to incoming shifts, there was also a group who could not even imagine whether staff passed on information that the next shift would need to know:

I've never really thought about that. (Resident 16)

I don't know. I haven't a clue. I never think of it. I don't know. I have no idea. (Resident 1 )

In contrast, three residents described occasions when they felt information had not been passed well between shifts or when they felt they had been given limited information.

Two residents voiced particularly strong opinions about the lack of availability of staff during handover periods which impacted negatively on their well-being and physical care as staff were not available to assist with using the toilet, resulting in the residents needing to wear incontinence pads.

Family members were mainly confident that the necessary information was passed on between shifts and that the care homes caring for their relatives were doing this well. There were a few exceptions, some of which were more about care home policies and frontline worker decisions about communication with residents or relatives, rather than ineffective information-sharing or lack of availability at handover. One relative highlighted how certain information may be handed over once, but not twice, or may be overlooked, which had happened in her experience during periods where certain support needs (eg, assistance with eating) fluctuated. Most relatives considered that current communication from the homes met their informational needs or they spoke to staff directly about their relative when visiting, either to gain or to give information.

Family members' and residents' views on the length of shifts worked by care staff suggested high confidence in the effectiveness of handovers and the quality of care provided by staff. Their view, generally, was that quality of care did not suffer because staff worked long shifts, although two residents and one relative had noticed staff being less attentive towards the end of their shifts. Nevertheless, there were also inferences of slightly lower confidence in the effectiveness of handovers in homes operating more than two shifts than initially apparent. Of the nine participants who said they preferred long shifts to minimise the number of handovers, two-thirds were linked with the homes operating three or four handovers and only one-third with homes operating only two handovers.

All family members thought that staff attending handovers should be paid for time spent in handover as handovers were important; our previous study ${ }^{14}$ found that they were not always paid. Many family members were unsurprised to hear that staff were not always paid for handovers and disapproved of this to differing degrees.

\section{DISCUSSION}

This study found that handovers between incoming and outgoing shifts tended to be largely invisible processes that many residents and relatives had given little thought to in terms of handover practice, logistics or effectiveness before participating in this study. It has underlined variations in awareness and understanding of handovers, handover practices, their purpose and effectiveness among residents and their relatives. Such variation might be expected as older people with a wide range of needs live in care homes (with or without nursing) and their individual preferences and personalities inevitably differ, as do hospital patients'. ${ }^{10} 20$

There appeared to be an underlying assumption that the administrative procedures necessary in care homes (such as handovers between shifts) would simply operate without input from residents or relatives. Yet being involved in care planning and evaluation is one of the factors that shape older people's experience of care and creates a sense of personal significance. ${ }^{21}$ In hospital settings, benefits for patients of being involved in handover discussions include feeling valued, ${ }^{22}$ being better informed about their situation, ${ }^{6}$ more satisfied, having an opportunity to amend inaccuracies ${ }^{8}$ or request clarifications $^{23}$ and, potentially, improved staff-patient communications. ${ }^{4-6}$ Advancing involvement in handovers in care homes will not necessarily be straightforward given that even bedside handovers do not automatically imply awareness of their content or involvement by their 'subjects', ${ }^{22}$ particularly since many residents are sleeping at handover times, as in hospitals, ${ }^{612}$ or may be hearing or cognitively impaired. Logistically, involvement is also time 
intensive, ${ }^{8}$ and care homes face substantial staffing challenges of both turnover and vacancies. ${ }^{24}$ In our previous study, care home staff did not mention involvement of residents as part of what happened in handovers between shifts. ${ }^{14}$ Several contributory factors may be responsible for participants' assumption about handovers operating without their input.

Among residents in this study, there was some recognition that their home was also the workplace of the staff who looked after them. Kenkmann $e t a l^{25}$ concluded that the two worlds of home and workplace coexist separately in the eyes of residents and staff. It is possible that participating residents felt no need, or did not feel entitled, to straddle the divide.

There may also be a connection with the difference in purpose between hospitals, where handovers are more visible, and care homes. The former centres on treatment or recovery, followed by discharge, whereas people often live in care homes until they die. Residents and relatives, therefore, may not experience a pressing need for information about transfer or discharge timing. Indeed, it was the longer-stay hospital patients whose health status did not change daily who were less likely to be interested in handover involvement in Jeffs $e t$ al's study. ${ }^{6}$ Average length of stay in a care home for older people is now 30 months. ${ }^{26}$ Many residents, therefore, have been in the home longer than many staff.

Residents' lack of attention to shift handover details may reflect their apparent assumption that such routine administrative procedures were effective and feelings of being known by (key) staff. Alongside their confidence in the care the home provided, relatives' general lack of knowledge of and interest in handovers may reflect the effectiveness and appropriateness of care homes' communication with relatives. While these perspectives may reflect a tendency to accept whatever care is provided due to low expectations or fear, ${ }^{27} 28$ these relatives' confidence in care challenges a discourse in the UK that most care is failing and of poor quality. ${ }^{29}$

We acknowledge limitations to this study which mean that evidence of generalisability would require a larger study. As all participating homes were CQC-rated as Good, their managers may have been better informed about good practice and more confident in allowing researchers entry. Involving care home managers in identifying potential participants means that certain residents or visitors known to hold negative views may have been screened out, although we felt that some managers may have done the opposite. We were informed that, in some homes, most residents were too frail or lacked capacity to take part in an interview. Our approach was designed to facilitate the participation of those residents able to consent to observations but not an interview. However, we were unable to recruit any resident in this category. It is possible that managers, in identifying potential participants, did not understand our rationale for wanting to include this group, or purposefully selected residents whom they felt would enjoy a conversation with a visiting researcher. Nevertheless, some participants were family members of residents lacking capacity to consent to an interview; in interviewing such relatives, the situations of some residents may have been taken into account, but through others' eyes, valuable as this is. ${ }^{29}$ Despite the strength of a research team holding a range of expertise and backgrounds, inconsistency in data collection is a risk. Our approach to data collection and analysis meant that one researcher had an overview of all participating homes and data, while the experiences and varied expertise of the whole team informed the project and participating homes did not have the disruption of multiple visitors. Participation among care home residents and their relatives from Asian backgrounds was very low $(n=2)$. Although we employed recommended strategies to maximise recruitment, such as the researcher being of matched ethnicity, face-to-face and gatekeeper referrals, poster recruitment, using researcher photos in recruitment materials and data collection in a familiar place, ${ }^{30}$ we noted a tendency for family members to prevent willing residents' participation due to concerns about the possible impact on a resident's care.

\section{CONCLUSION}

Care transitions are often thought about as transfer to care or hospital, for example, not as transitions within care settings, that is, between shifts, 'floors' or units within care/nursing homes, between homes, or between different specialists. For continuity of care and quality of life, it is important to consider these other dimensions. This study has progressed the evidence about shift handovers from the perspectives of care home residents and their relatives. The setting appears to influence awareness and knowledge of and levels of interest in involvement in handovers, as do perspectives of their effectiveness. Further research could usefully address differences in perspectives of residents with different assistance needs, handovers when moving between units/floors within care homes or from independent units to supported units within care homes, or moving between homes.

\section{Twitter Katharine Orellana @katitao}

Acknowledgements We thank the care homes' owners and managers who helped with this study and the residents and family members who took part in interviews and participated in observations. All those participating were offered a certificate of participation in research. We thank the Study Advisory Group and the Service User and Carer Group for their input to and consideration of this study. The study was funded by the Abbeyfield Research Foundation and we are most grateful for its support. The views and opinions in this report are those of the authors and should not be interpreted as those of the funders of their research. We thank the peer reviewers for their constructive comments.

Contributors JM, CN and JoM developed the initial research concept for this study, and JoM and CN assisted with initial study design. All authors further developed the protocol, each making substantial contributions to the study's design and planning. KO, VL, JoM, CN and RE undertook recruitment and data collection. KO managed the data and undertook initial analysis. All authors discussed analysis and interpretation of the data in team meetings and electronically during writing up. JM guided and supported the study throughout. KO drafted the manuscript which was then revised critically for intellectual content by all other authors. All authors approved the final manuscript and agree to be accountable for its content. The 
Study Advisory Group and Service User and Carer Group contributed to the planning of this study and gave critical comments on our interpretation of the findings.

Funding This work was supported by The Abbeyfield Research Foundation.

Disclaimer The views expressed here are those of the authors and not the funder. The funder was not involved in the execution, analysis and interpretation of data, or the writing of this paper. All authors are independent of the funder and were involved in data analysis.

Competing interests None declared.

Patient consent for publication Not required.

Ethics approval Ethical approval was obtained from the Health Research Authority's Social Care Research Ethics Committee (Ref no. 18/IEC08/0001).

Provenance and peer review Not commissioned; externally peer reviewed.

Data availability statement The authors declare that all data supporting the findings of this study reported in this article are available within the article. This manuscript is an honest, accurate, and transparent account of the study being reported; no important aspects of the study relating to the topic of this paper have been omitted.

Open access This is an open access article distributed in accordance with the Creative Commons Attribution Non Commercial (CC BY-NC 4.0) license, which permits others to distribute, remix, adapt, build upon this work non-commercially, and license their derivative works on different terms, provided the original work is properly cited, appropriate credit is given, any changes made indicated, and the use is non-commercial. See: http://creativecommons.org/licenses/by-nc/4.0/.

\section{ORCID iDs}

Katharine Orellana http://orcid.org/0000-0002-1315-3706

Valerie Lipman http://orcid.org/0000-0002-5958-7155

Jill Manthorpe http://orcid.org/0000-0001-9006-1410

Jo Moriarty http://orcid.org/0000-0003-1574-1242

Caroline Norrie http://orcid.org/0000-0001-6715-9305

Rekha Elaswarapu http://orcid.org/0000-0002-7695-931X

\section{REFERENCES}

1 Lievesley N, Crosby G, Bowman C. The changing role of care homes. London: BUPA and Centre for Policy on Ageing, 2011.

2 Quince C. Low expectations: attitudes on choice, care and community for people with dementia in care homes. London: Alzheimer's Society, 2013.

3 Orellana K. Care home managers: a scoping review of evidence. London: NIHR School for Social Care Research, 2014.

4 Cohen MD, Hilligoss PB. The published literature on handoffs in hospitals: deficiencies identified in an extensive review. BMJ Qual Saf 2010;19:493-7.

5 Ferguson TD, Howell TL. Bedside reporting: protocols for improving patient care. Nurs Clin North Am 2015;50:735-47.

6 Jeffs L, Beswick S, Acott A, et al. Patients' views on bedside nursing handover: creating a space to connect. J Nurs Care Qual 2014;29:149-54.

7 Moriarty JO, Lipman V, Norrie C, et al. Handovers in care homes for older people - their type, timing and usefulness. findings from a scoping review. Ageing Soc 2019;39:851-71.

8 McMurray A, Chaboyer W, Wallis M, et al. Patients' perspectives of bedside nursing handover. Collegian 2011;18:19-26.
9 Bruton J, Norton C, Smyth N, et al. Nurse handover: patient and staff experiences. Br J Nurs 2016;25:386-93.

10 Whitty JA, Spinks J, Bucknall T, et al. Patient and nurse preferences for implementation of bedside handover: do they agree? Findings from a discrete choice experiment. Health Expectations 2017;20:742-50.

11 Manias E, Watson B. Moving from rhetoric to reality: patient and family involvement in bedside handover. Int $J$ Nurs Stud 2014;51:1539-41.

12 Bradley S, Mott S. Adopting a patient-centred approach: an investigation into the introduction of bedside handover to three rural hospitals. J Clin Nurs 2014;23:1927-36.

13 Wilberforce M, Challis D, Davies L, et al. Person-centredness in the community care of older people: a literature-based concept synthesis. Int J Soc Welf 2017;26:86-98.

14 Norrie C, Lipman V, Moriarty J, et al. How do handovers happen? A study of handover-at-shift changeovers in care homes for older people. London: King's College London, Social Care Workforce Research Unit, 2017.

15 Wall SS. Focused ethnography: a methodological adaptation for social research in emerging contexts. Forum: Qualitative Social Research 2014;16.

16 Luff R, Ferreira Z, Meyer J, et al. SSCR methods review 8. London: NIHR School for Social Care Research, 2011.

17 Patton MQ. Qualitative evaluation and research methods. 3rd edn. Thousand Oaks, CA: Sage Publications, Inc, 2002.

18 Spradley J, Rinehart H W. Participant observation. New York: Holt: Rinehart and Winston, 1980.

19 Miles MB, Huberman AM. Qualitative data analysis: an expanded sourcebook. London: SAGE Publications, 1994.

20 Drach-Zahavy A, Shilman O. Patients' participation during a nursing handover: the role of handover characteristics and patients' personal traits. J Adv Nurs 2015;71:136-47.

21 Nolan MR, Brown J, Davies S, et al. The senses framework: improving care for older people through a relationship-centred approach. getting research into practice (grip) report no 2. Sheffield Hallam University, 2006. http://shura.shu.ac.uk/280/

22 Chaboyer W, McMurray A, Wallis M. Bedside nursing handover: a case study. Int J Nurs Pract 2010;16:27-34.

23 Tobiano G, Chaboyer W, McMurray A. Family members' perceptions of the nursing bedside handover. J Clin Nurs 2013;22:192-200.

24 Moriarty J, Manthorpe J, Harris J. Recruitment and retention in adult social care services. King's College London: Social Care Workforce Research Unit, 2018.

25 Kenkmann A, Poland F, Burns D, et al. Negotiating and valuing spaces: The discourse of space and 'home' in care homes. Health Place 2017:43:8-16.

26 LaingBuisson. Care of older people: UK market report. London: LaingBuisson, 2017.

27 Bowers H, Clark A, Crosby G, et al. Older people's vision for longterm care. York: Joseph Rowntree Foundation, 2009.

28 Welch E, Palmer S, Towers A-M, et al. Why are relatives of care home residents reluctant to "rock the boat"? Is there a culture of acceptance? Working with Older People 2017;21:124-32.

29 Manthorpe J, Njoya E, Harris J, et al. Media reactions to the Panorama programme "Behind Closed Doors: Social Care Exposed" and care staff reflections on publicity of poor practice in the care sector. J Adult Prot 2016;18:266-76.

30 Liljas AEM, Walters K, Jovicic A, et al. Strategies to improve engagement of 'hard to reach' older people in research on health promotion: a systematic review. BMC Public Health 2017;17:349. 